\title{
Adenosine administration in supraventricular tachycardia
}

\author{
P. Robles Velasco ${ }^{1}$ I. Monedero Sánchez ${ }^{1}$ A. Rubio Caballero ${ }^{1}$ M. Chichakli Cela ${ }^{1}$ Y. González Doforno ${ }^{1}$
}

\begin{abstract}
Answer
The ECG during symptoms was strongly suggestive of typical atrial flutter. After adenosine administration, the heart rate slowed for a few seconds because of 3:1 atrioventricular (AV) conduction, but it then changed to $1: 1$ conduction response (Fig. 1). This was associated with haemodynamic instability, which required electrocardioversion. Although adenosine administration is usually innocuous, its potential harmful effects should not be underestimated. A careful analysis of the initial ECG could have foreseen this atypical response, as 1:1 AV conduction beats were observed [1]. These beats are indicators of a high sympathetic tone, which increased after adenosine administration, with the outcome described above [2]. This case shows the unusual but dangerous proarrhythmic effect of adenosine in patients with atrial flutter, after producing important sympathetic discharge and subsequent 1:1 AV conduction, as well as the presence of predictors in the ECG which discourage its administration [3].
\end{abstract}

\section{Conclusion}

Atrial flutter with 1:1 atrioventricular conduction after administration of adenosine.

Conflict of interest P. Robles Velasco, I. Monedero Sánchez, A. Rubio Caballero, M. Chichakli Cela and Y. González Doforno declare that they have no competing interests.

P. Robles Velasco

problesve.pr@gmail.com

1 Cardiology Unit, Hospital Universitario Fundación Alcorcon, Madrid, Spain
Open Access This article is distributed under the terms of the Creative Commons Attribution 4.0 International License (http:// creativecommons.org/licenses/by/4.0/), which permits unrestricted use, distribution, and reproduction in any medium, provided you give appropriate credit to the original author(s) and the source, provide a link to the Creative Commons license, and indicate if changes were made.

\section{References}

1. Slade AK, Garratt CJ. Proarrhythmic effect of adenosine in a patient with atrial flutter. Br Heart J. 1993;70:91-2.

2. Rotondi F, Lanzillo T, Manganelli F, et al. Atypical response of class IC atrial flutter to adenosine. Monaldi Arch Chest Dis. 2011;76:151-4.

3. Mallet ML. Proarrhythmic effects of adenosine: a review of the literature. Emerg Med J. 2004;21:408-10. 


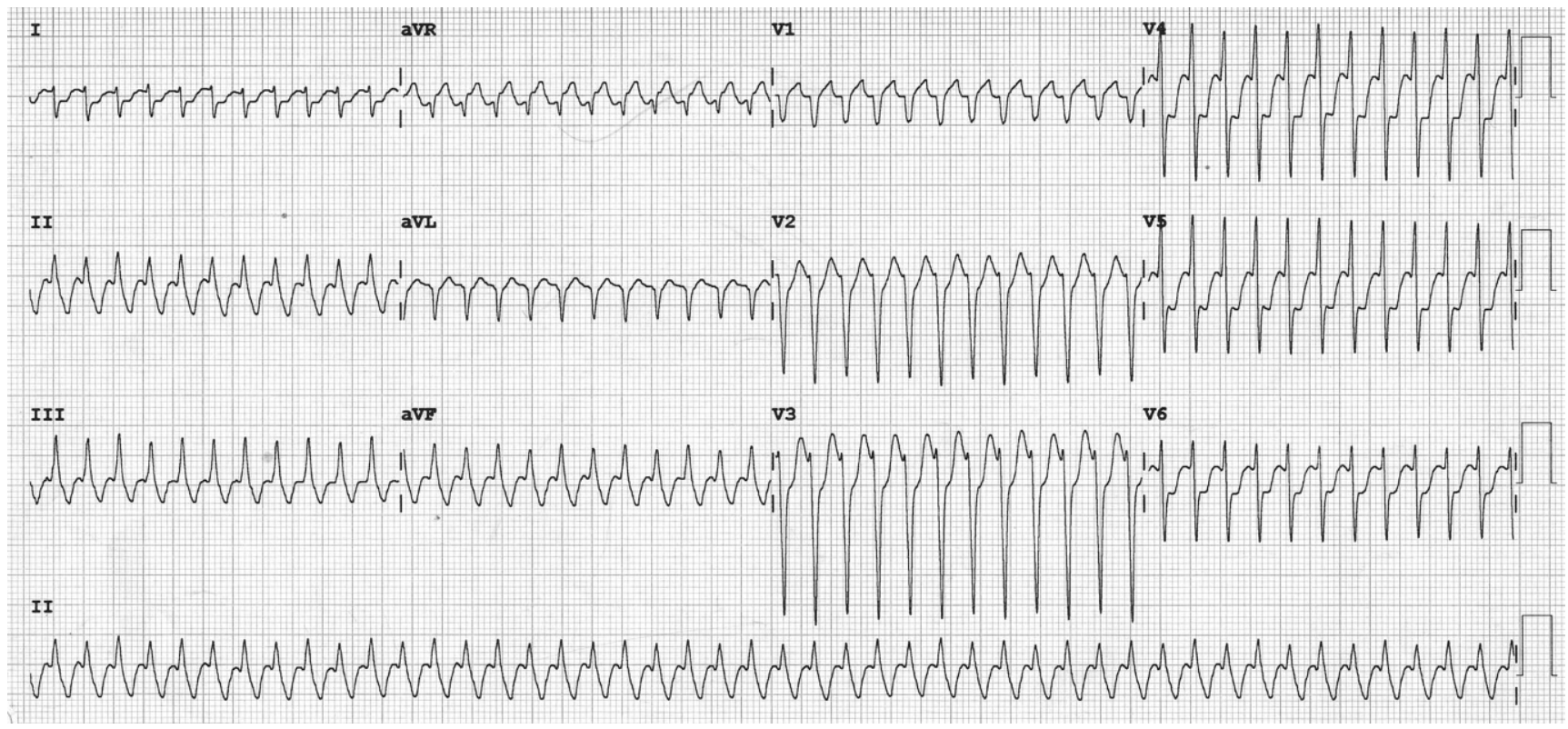

Fig. 1 ECG after administration of adenosine. Atrial flutter with 3:1 atrioventricular conduction was initially observed for a few seconds, but it then changed to 1:1 atrioventricular conduction, showing the potential proarrhythmic effect of adenosine 